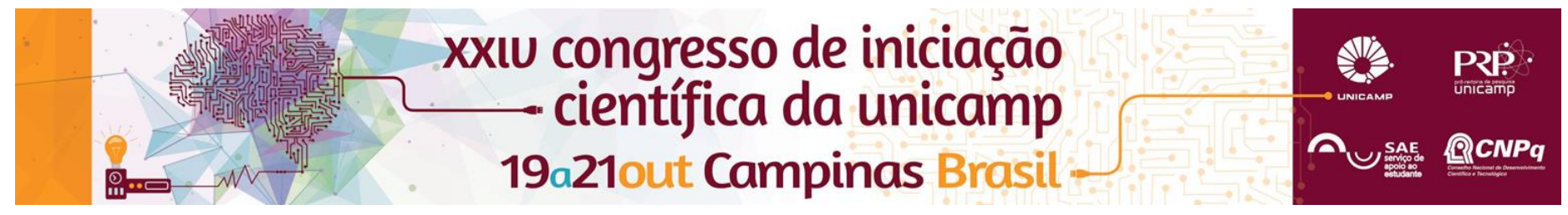

\title{
Ensinando a pesquisar: os impactos afetivos de um Projeto de Ciências em alunos do Ensino Fundamental II
}

\author{
Sérgio Antônio da Silva Leite, Patrícia Fracetto* - Faculdade de Educação (FE)
}

\begin{abstract}
Resumo
A presente pesquisa tem por objetivo analisar os impactos afetivos causados em alunas participantes de um Projeto de Ciências, realizado em uma escola municipal de Ensino Fundamental da cidade de Americana-SP. Pretende-se destacar os aspectos afetivos presentes no processo de mediação pedagógica, durante orientação e realização das atividades dos envolvidos do Projeto considerando a formação dos sujeitos tanto intelectual quanto afetiva. Por ser uma pesquisa com abordagem metodológica qualitativa, descrita por Lüdke \& André (1986) e Bodgan \& Biklen (1997), a mesma visa elucidar o universo de significações de um grupo de três alunas participantes do Projeto, do 8o ano do Ensino Fundamental II, bem como da professora-orientadora do grupo. A pesquisa fundamenta-se em teorias da área da Psicologia, como Vygotsky $(1998,2001)$ e Wallon $(1979,1995)$, contando também com estudos de Leite e colaboradores (2006, 2014). A coleta de dados será realizada através do procedimento de Entrevistas Recorrentes subsidiado por Zanelli (1998), sendo que os dados serão agrupados, analisados e discutidos através de núcleos de significação com base na abordagem teórica assumida. A relevância da pesquisa reside na importância expressa pela efetivação, no ambiente escolar, do ensino de objetos culturais a partir de experiências, que, baseando-se em pesquisas, podem contribuir na formação de educandos protagonistas nas relações de conhecimento, além de contribuir com pesquisas relacionadas com a temática da Afetividade.
\end{abstract}

Palavras-chave:

Afetividade nas práticas pedagógicas, Ensino de Ciências, Iniciação Científica no Ensino Fundamental.

\section{Introdução}

Com o intuito de analisar os impactos afetivos em sujeitos participantes de um Projeto de Ciências, que visa colocar os alunos do Ensino Fundamental II em contato com as práticas de pesquisas científicas, a pergunta feita nesta investigação foi: será que as condições de mediação e orientação do Projeto de Ciências estão produzindo uma aproximação afetivamente positiva com as práticas de pesquisa? Caso estejam, quais as características deste processo?

\section{Resultados e Discussão}

Oito entrevistas foram efetivadas, em seguida, transcritas e organizadas em núcleos temáticos, mediante destaques presentes nos relatos verbais dos sujeitos. Das oito entrevistas, sete foram realizadas com um grupo de alunas participantes do Projeto e uma com a professoraorientadora. Por enquanto, os dados coletados e agrupados em núcleos temáticos nesta pesquisa indicam que houve, de fato, uma apropriação dos objetos culturais pelo grupo de alunas entrevistadas nesta pesquisa. Sobre os momentos mais significativos destacados pelas alunas participantes, é preciso frisar: a participação em Mostras e Feiras de Ciências e divulgação científica; o envolvimento com o tema escolhido; as mediações precisas e encorajadoras da professora-orientadora; a utilização de redes sociais e plataformas interativas durante atividades do Projeto e o trabalho em grupo com pessoas amigas. Sobre a entrevista realizada com a professora-orientadora, é possível perceber que a mesma busca por novos conhecimentos, considerando-se, talvez, como um ser inacabado. Estas são considerações iniciais dos resultados desta pesquisa, pois espera-se aprofundar a análise dos dados e continuar ampliando as bases teóricas durante o segundo semestre de 2016.

\section{Conclusões}

Ressalte-se que, nessa fase inicial da análise dos dados, as alunas relatam sua internalização dos conhecimentos mediatizados pelo Projeto de Ciências, e também dizem que esta foi uma experiência significativa. Espera-se realizar, durante o segundo semestre de 2016, a caracterização das mediações e a identificação das ações concretas da professora-orientadora, que foram vistas pelos sujeitos, como facilitadores no processo de ensino e aprendizagem das atividades do Projeto. Esta pesquisa enseja contribuir, portanto, com estudos relacionados à afetividade nas práticas pedagógicas, com o Ensino de Ciências e pesquisas na área da Teoria Histórico-Cultural de Vygotsky e do Desenvolvimento Humano de Wallon.

\section{Agradecimentos}

À FAPESP - Fundação de Amparo à Pesquisa do Estado de São Paulo, pelo apoio recebido durante a pesquisa. Ao Comitê de Ética em Pesquisa, FCM - UNICAMP. Aos sujeitos participantes desta pesquisa.

BOGDAN, R. \& BIKLEN, S. K. Investigação Qualitativa em Educação: uma introdução à teoria e aos métodos. Portugal: Porto Editora, 1997.

LEITE, S. A. S. (org). Afetividade e Práticas Pedagógicas. São Paulo: Casa do Psicólogo, 2006.

LEITE, S. A. S. \& NOGUEIRA, B. M. A afetividade no processo de orientação de pesquisa científica. Rev. educ. PUC - Camp, Campinas, Vol. 19, nº3, set./dez., 2014, p. 249-259.

LÜDKE, M. \& ANDRÉ, M. E. A. Pesquisa em Educação: abordagens qualitativas. São Paulo: EPU, 1986.

VYGOTSKY, L. S. A formação social da mente. São Paulo: Martins Fontes, 1998 VYGOTSKY, L. S. A construção do pensamento e da linguagem. São Paulo: Martins Fontes, 2001

WALLON, H. Do acto ao pensamento. Lisboa: Moraes Editores, 1979.

WALLON, H. As origens do caráter na criança. São Paulo: Nova Alexandria, 1995 .

ZANELLI, J. C. Formação Profissional e Atividades de Trabalho: análise das necessidades identificadas por psicólogos organizacionais. Tese de Doutorado, Faculdade de Educação, Universidade Estadual de Campinas, 1992. 